ORIGINAL ARTICLE

\title{
Examination of lower-upper limb of power and force parameters of elite athletes
}

\author{
Samet Aktaş ${ }^{1 \mathrm{ACDE}}$, Oktay Çakmakçı1 ${ }^{2 \mathrm{ABDE}}$ \\ ${ }^{1}$ University of Batman, Batman, Turkey \\ ${ }^{2}$ University of Selcuk, Konya, Turkey
}

Authors' Contribution: A - Study Design, B - Data Collection, C - Statistical Analysis, D - Manuscript Preparation, E - Funds Collection

\begin{abstract}
Purpose: In this study, it is aimed to evaluate the power and force parameters of lower and upper extremities of the individual and team athletes who practice different branches.

Material: $\quad 32$ elite athletes, most of whom are university students, with an average age of $21.16 \pm 2.08$, who are active in sports, participated in the study. The groups were formed from Boxing and Handball (BG and HG) branches in which the upper extremities are used predominantly and from Taekwondo and Football (TG and FG) branches in which the lower extremities are used predominantly. The anaerobic power values of each individual's upper and lower extremities were measured by a Monark 894E. The isokinetic force values of dominant arms and legs were measured by a Cybex humac norm device.

Results: $\quad$ After examination of the data it was found that the upper extremity power values of BG and HG were significantly higher than TG when the top values of peak powers (PP) were evaluated. In the evaluations with respect to leg $60 \%$ and $180 \%$ s extension and flexion; HG and FG was significantly higher than TG in $60 \%$ extension at PP; HG and FG were significantly indifferent but they were significantly higher than BG and TG in $60 \%$ s flexion at PP. In the comparisons of the groups $60 \%$ and $180 \%$ s extension and flexion values of lower extremities anaerobic power and isokinetic force and lower extremities' wingate values, a number of positive relations were found between all of the groups. All of the groups were positively related to each other in terms of upper extremities wingate and $60 \% \mathrm{~s}, 180 \% \mathrm{~s}$ internal and external isokinetic forces.

Conclusions: Both the isokinetic arm force values and arm wingate levels were higher in the branches in which the upper extremities are used predominantly than the branches in which the lower extremities are used predominantly. On the other hand, the difference seen in the upper extremities was not seen in the lower extremities.

Keywords: $\quad$ anaerobic power, extremity, isokinetic force, peak powers
\end{abstract}

\section{Introduction}

Athletics not only have many physical effects on human body but also increase the prestige of nations and have positive effects on morale structure of societies [1]. The high-level performance of athletes is characterized as a whole in the concept of being the proof of physiological and psychological factors. Because of this, the scientists in athletics area conclude that the scientific researches and trial-and-error method are more useful than the observational results throughout the period in which athletes prepare for their athletics competition [2].

Isokinetic means constant speed. Isokinetic power means the maximum power generated by some muscle or muscle groups against a stable object. The tension arisen from the isokinetic contractions of a muscle has a constant speed (iso-kinetic) throughout the joint's range of motion and is at the maximum level [3].

Regularly assessing anaerobic power is important for athletes from sports with an explosive strength component [4]. Anaerobic power is the one of the two components of anaerobic performance. The power is the highest power amount gained in one unit of time at the explosive type loads. Anaerobic power depends on the ATP-PC system in terms of regeneration of ATP at intense

(c) Samet Aktaş, Oktay Çakmakçı, 2020

doi:10.15561/20755279.2020.0606 loads [4]. Alactic anaerobic power is very important when the explosive moves lasting up to 8 seconds are needed in such conditions as $100 \mathrm{~m}$ sprint, weight lifting, boxing, wrestling and fencing [5].

This study was conducted to determine the anaerobic power and isokinetic force levels of upper and lower extremities of the individuals who are actively engaged in athletics in elite level.

\section{Material and Methods}

\section{Participants}

32 male elite athletes whose (most of whom are university students) with an average age of 21.16 \pm 2.08 (average height is $177.59 \pm 7.49 \mathrm{~cm}$ and average body weight is $79.66 \pm 2.68 \mathrm{~kg}$ ), participated in the study. The boxing and taekwondo athletes were chosen among the professional athletes who were at the national team level, the handball athletes were at the super league level of Turkey and the football athletes were at the third league level of Turkey at least. 8 athletes were participated in each branch for this research.

The participants were tested 2 hours after their breakfast. The measurements of upper and lower extremities' anaerobic power and isokinetic force were taken between 9:00-11:00 a.m. in different days. The measurements were taken as wingate upper and lower 
tests on Tuesday and Wednesday, and as isokinetic arm and leg tests on Thursday and Friday.

This study was conducted in accordance with the 19.12.2017 dated and 2017/5 numbered decree of noninvasive clinical research ethics committee of Sport Sciences Faculty of Selçuk University.

Wingate Anaerobic Test

For the wingate test, a Monark 894E arm and leg cycle ergometer with weight basket (Made in Sweden) that was connected to computer modified for the test and that had the compatible software for the computer was used. The machine was adjusted according to each one of the athletes' height before the test. The load used as the external resistance on the ergometer was determined as 50 $\mathrm{gr} / \mathrm{kg}$ for the arm and $75 \mathrm{gr} / \mathrm{kg}$ for the leg. The participants were asked to pedal at their highest speed for 30 seconds against the resistance and they were supported verbally to be able to show a high performance [6].

\section{Isokinetic Strenght Test}

The participants' internal and external rotation concentric force of the dominant arm's shoulder was measured from 5 submaximal repetition at $60 \%$ and $180 \%$ s angular velocity. These 5 repetitions were measured after 3 submaximal preliminary repetition of exercises at the same angular velocities and a relaxation period. The isokinetic force of the dominant leg was measured at $60 \% \mathrm{~s}$ velocity with 5 repetition and $180^{\circ}$ s with 15 repetition. 30 seconds breaks were given between the $60 \%$ s and $180^{\circ} / \mathrm{s}$ angular velocities. The measurements were taken by Humac NORM isokinetic dynamometer (Lumex Inc,
Ronkonkoma, New York, USA) which's reliability and validity have been proven through different studies [7].

Statistical Analyses

SPSS 22 package program was used for the statistical analyses of the data. The parameters and standard deviations of all subjects are given. To look at the normality of the data belongs to the study, Shapiro-Wilk test was used. Among the normally distributed data, independent sample $t$ test was used for the binary variables, one way analysis of variance (Anova) was used for the comparisons of branches and to be able to determine that which group is the source of difference LSD and Tukey tests which belong to post hoc tests family were conducted. The correlation matrix was used for the relational approach. The level of statistical significance was taken as 0.05 .

\section{Results}

As shown in Table 1, the average age of boxers among the participants was $21.38 \pm 2.39$, their average height was $172.50 \pm 8.43$, the average body weight was $69.00 \pm 10,58$. The average age of handball athletes was $20.75 \pm 2.43$, their average height was $182.25 \pm 6,36$ and the average body weight was $89.50 \pm 23.24$. The average age of footballers was $22.13 \pm 1.25$, the average height was $179.38 \pm 4.03$ and the average body weight was $72.87 \pm 7.27$. The average age of taekwondo athletes was $21.16 \pm 2.08$, the average height was $177.59 \pm 7.49$ and their average body weight was $79.66 \pm 21.68$. The participants' age and height values were all statistically similar. The body weights of HG were significantly different from the other three groups $(p<0.05)$. The rest results are in tables 2-7.

Table 1. Descriptive information of the participants.

\begin{tabular}{llllll}
\hline \multirow{2}{*}{ Parameters } & Branches & & & & \\
\cline { 2 - 6 } & BG & HG & FG & TG & Total \\
\cline { 2 - 6 } & Mean \pm SD & Mean $\pm S D$ & Mean $\pm S D$ & Mean $\pm S D$ & Mean $\pm S D$ \\
\hline Age(year) & $21.38 \pm 2.39^{\mathrm{a}}$ & $20.75 \pm 2.43^{\mathrm{a}}$ & $22.13 \pm 1.25^{\mathrm{a}}$ & $20.38 \pm 2.00^{\mathrm{a}}$ & $21.16 \pm 2.08$ \\
Height $(\mathrm{cm})$ & $172.50 \pm 8.43^{\mathrm{a}}$ & $182.25 \pm 6.36^{\mathrm{a}}$ & $179.38 \pm 4.03^{\mathrm{a}}$ & $176.25 \pm 7.78^{\mathrm{a}}$ & $177.59 \pm 7.49$ \\
Body weight $(\mathrm{kg})$ & $69.00 \pm 10.58^{\mathrm{b}}$ & $89.50 \pm 23.04^{\mathrm{a}}$ & $72.87 \pm 7.27^{\mathrm{b}}$ & $74.75 \pm 9.18^{\mathrm{b}}$ & $79.66 \pm 21.68$ \\
\hline
\end{tabular}

Note. BG - Boxing Group, HG - Hendball Group, FG - Football Group,TG - Taekwondo Group. a, b - The difference between the averages with different letters in the same row are statistically significant $(P<0.05)$.

Table 2. Wingate results of participants' upper and lower extremities categorized in branches

\begin{tabular}{|c|c|c|c|c|c|c|}
\hline \multirow[b]{2}{*}{ Wingate } & \multirow[b]{2}{*}{ Group } & \multicolumn{3}{|l|}{ Lower Limb } & \multicolumn{2}{|l|}{ Upper Limp } \\
\hline & & Mean \pm SD & Letter & Group & Mean $\pm S$ & Letter \\
\hline \multirow{3}{*}{ PP (W) } & $\mathrm{BG}$ & $725.54 \pm 157.83$ & $\mathrm{~b}$ & BG & $894.96 \pm 146.32$ & $a$ \\
\hline & HG & $934.94 \pm 165.62$ & a & HG & $802.69 \pm 263.09$ & a \\
\hline & FG & $844.85 \pm 133.37$ & $a b$ & $\mathrm{FG}$ & $\begin{array}{l}682.82 \pm 64.83 \\
53998+12957\end{array}$ & $a b$ \\
\hline \multirow{4}{*}{$\mathrm{RPP}(\mathrm{W} / \mathrm{kg})$} & BG & $10.58 \pm 1.27$ & $\frac{D}{a b}$ & BG & $13.19 \pm 2.70$ & $a$ \\
\hline & HG & $10.34 \pm 2.36$ & $a b$ & HG & $9.64 \pm 3.93$ & $a b$ \\
\hline & FG & $11.75 \pm 1.98$ & $a$ & FG & $9.30 \pm 1.00$ & $b$ \\
\hline & TG & $9.34 \pm 1.36$ & $\mathrm{~b}$ & TG & $7.11 \pm 2.09$ & b \\
\hline \multirow{4}{*}{$\mathrm{AP}(\mathrm{W})$} & $B G$ & $520.82 \pm 91.87$ & $\mathrm{~b}$ & $B G$ & $454.83 \pm 53.29$ & a \\
\hline & HG & $634.60 \pm 96.79$ & a & HG & $447.13 \pm 65.29$ & a \\
\hline & FG & $604.94 \pm 69.89$ & $a b$ & FG & $387.15 \pm 34.30$ & $a b$ \\
\hline & TG & $542.73 \pm 83.57$ & b & TG & $346.86 \pm 54.53$ & b \\
\hline \multirow{4}{*}{ RAP (W/kg) } & BG & $7.56 \pm 1.03$ & - & BG & $6.78 \pm 0.89$ & a \\
\hline & HG & $7.26 \pm 1.09$ & - & HG & $5.29 \pm 1.11$ & $b$ \\
\hline & FG & $7.91 \pm 0.25$ & - & FG & $5.11 \pm 0.56$ & b \\
\hline & TG & $7.13 \pm 0.80$ & - & TG & $4.43 \pm 0.92$ & b \\
\hline
\end{tabular}

Note. $a, b$ - The difference between the averages in the same column is significant $(P<0.05)$. BG - Boxing Group, HG - Hendball Group, FG - Football Group,TG - Taekwondo Group. PP - Peak Power, RPP - Relative Peak Power, AP - Avarage Power, RAP - Relative Avarage Power 
Table 3. Dominant arm and leg isokinetic test results of the participants at $60^{\circ} / \mathrm{s}$ and $180^{\circ} / \mathrm{s}$ rotation

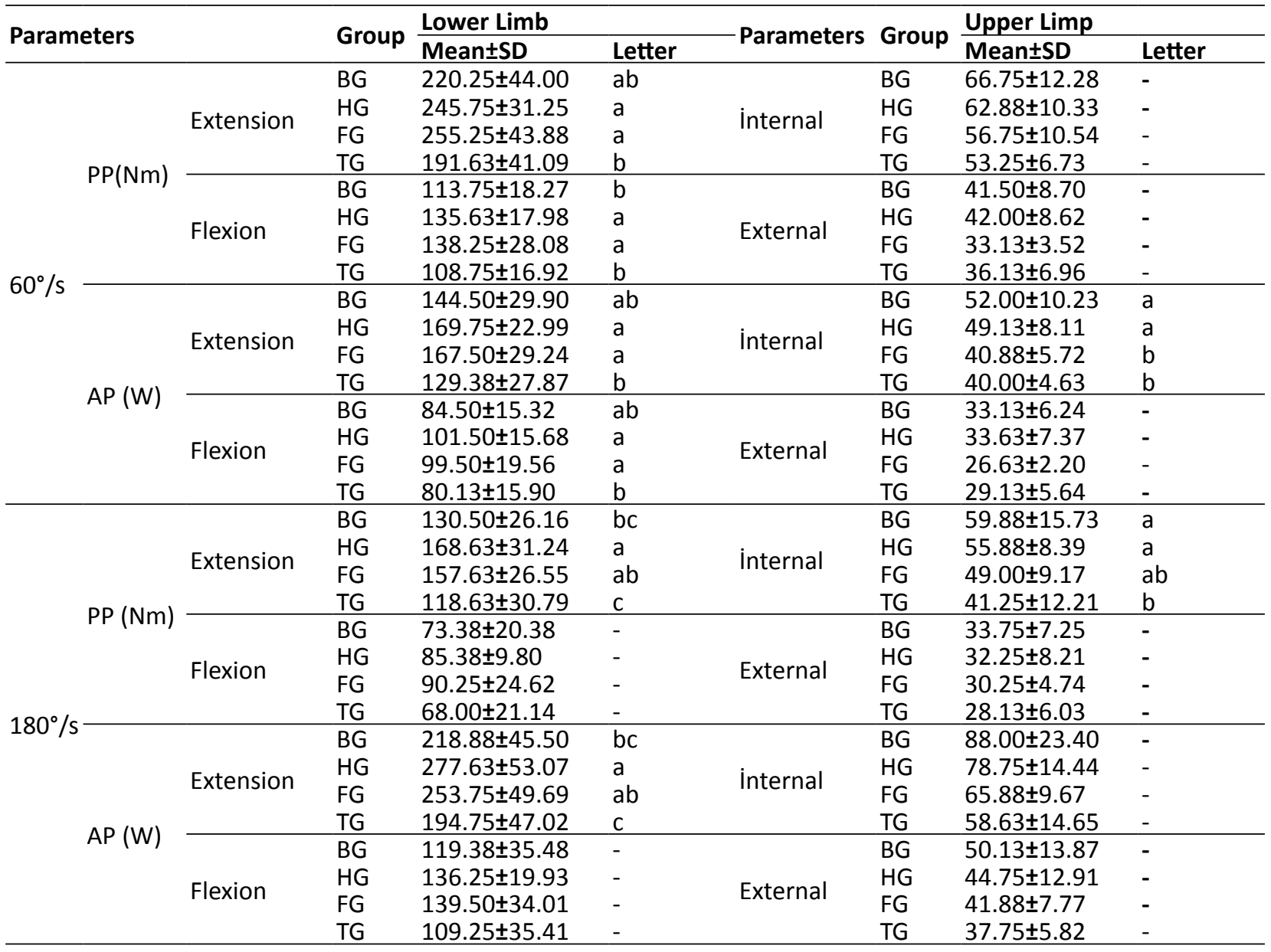

Note. $a, b, c$ - The difference between the averages in the same column is significant $(P<0.05)$. BG - Boxing Group, HG - Hendball Group, FG - Football Group,TG - Taekwondo Group. PP - Peak Power, RPP - Relative Peak Power, AP - Avarage Power, RAP - Relative Avarage Power.

Table 4. The correlation analysis of the participants' wingate data and dominant arm and leg $60^{\circ} / \mathrm{s}$ and $180^{\circ} / \mathrm{s}$ rotation isokinetic data categorized in branches.

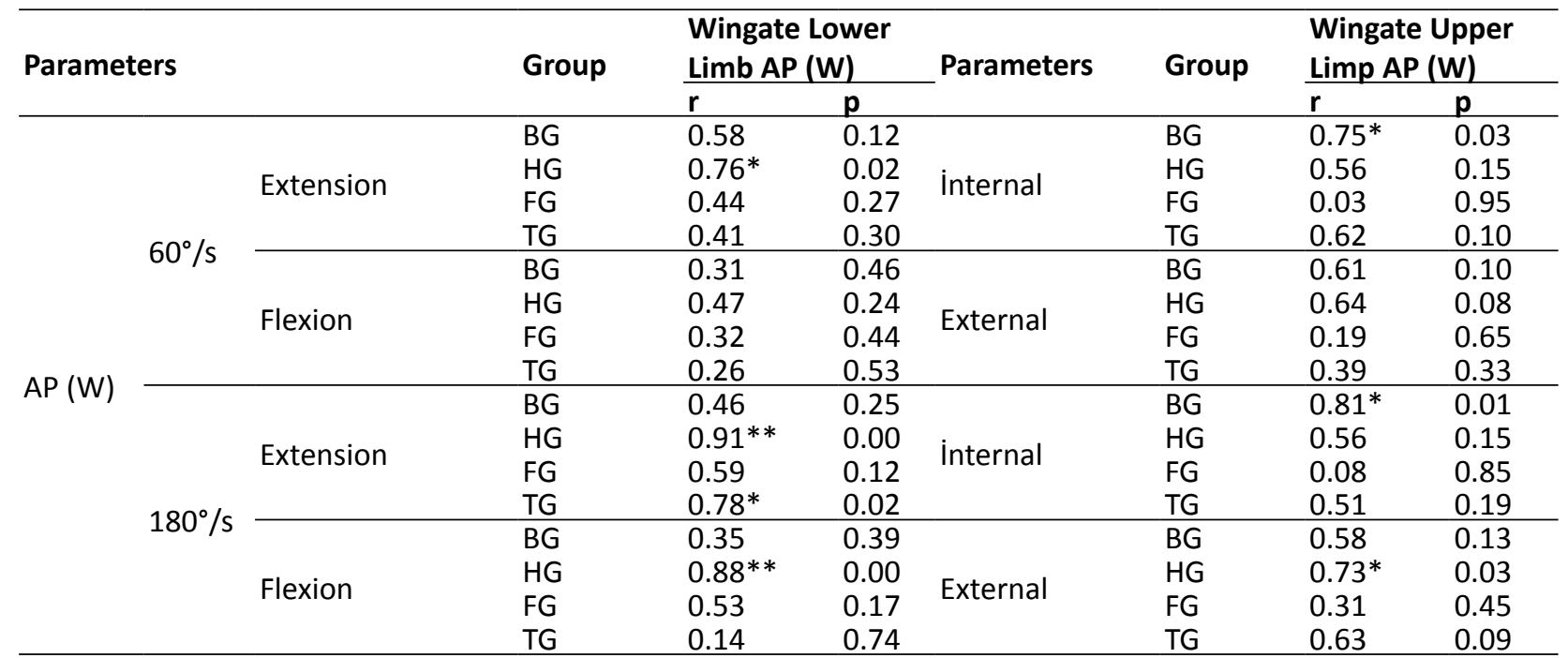

Note. ${ }^{* *}$ Correlation is significant at 0.01 level. ${ }^{*}$ Correlation is significant at 0.05 level. AP: Avarage Power. BG - Boxing Group, HG - Hendball Group, FG - Football Group,TG - Taekwondo Group. 
Table 5. Wingate test results of the participants in terms of extremity dominancy

\begin{tabular}{|c|c|c|c|c|c|c|}
\hline \multirow{2}{*}{ Parameters } & \multirow{2}{*}{ Group } & \multicolumn{2}{|l|}{ Lower Limb } & \multirow{2}{*}{ Group } & \multicolumn{2}{|l|}{ Upper Limp } \\
\hline & & Mean $\pm S D$ & $p$ & & Mean $\pm S D$ & $p$ \\
\hline PP (W) & $\begin{array}{l}\text { ÜEASB } \\
\text { AEASB }\end{array}$ & $\begin{array}{l}830.24 \pm 190.05 \\
778.62 \pm 141.29\end{array}$ & 0.47 & $\begin{array}{l}\text { ÜEASB } \\
\text { AEASB }\end{array}$ & $\begin{array}{l}848.82 \pm 211.10 \\
611.40 \pm 123.44\end{array}$ & $0.00 *$ \\
\hline RPP (W/kg) & $\begin{array}{l}\text { ÜEASB } \\
\text { AEASB }\end{array}$ & $\begin{array}{l}10.46 \pm 1.84 \\
10.54 \pm 2.06\end{array}$ & 0.89 & $\begin{array}{l}\text { ÜEASB } \\
\text { AEASB }\end{array}$ & $\begin{array}{l}11.41 \pm 3.74 \\
8.21 \pm 1.95\end{array}$ & $0.00 *$ \\
\hline AP (W) & $\begin{array}{l}\text { ÜEASB } \\
\text { AEASB }\end{array}$ & $\begin{array}{l}577.71 \pm 108.46 \\
573.84 \pm 81.06\end{array}$ & 0.91 & $\begin{array}{l}\text { ÜEASB } \\
\text { AEASB }\end{array}$ & $\begin{array}{l}463.67 \pm 121.51 \\
367.00 \pm 48.68\end{array}$ & $0.00 *$ \\
\hline RAP $(W / k g)$ & $\begin{array}{l}\text { ÜEASB } \\
\text { AEASB }\end{array}$ & $\begin{array}{l}7.41 \pm 1.04 \\
7.52 \pm 0.70\end{array}$ & 0.94 & $\begin{array}{l}\text { ÜEASB } \\
\text { AEASB }\end{array}$ & $\begin{array}{l}6.03 \pm 1.24 \\
4.76 \pm 0.81 \\
\end{array}$ & $0.00 *$ \\
\hline
\end{tabular}

Note. ${ }^{*} p<0.05$ ÜEASB=Boxing + Handball. AEASB= Football+Taekwondo. PP - Peak Power. RPP - Relative Peak Power. AP - Avarage Power. RAP - Relative Avarage Power

Table 6. Dominant arm and leg isokinetic force results of the participants at $60 \% \mathrm{~s}$ and $180^{\circ} / \mathrm{s}$ rotation in terms of extremity dominancy.

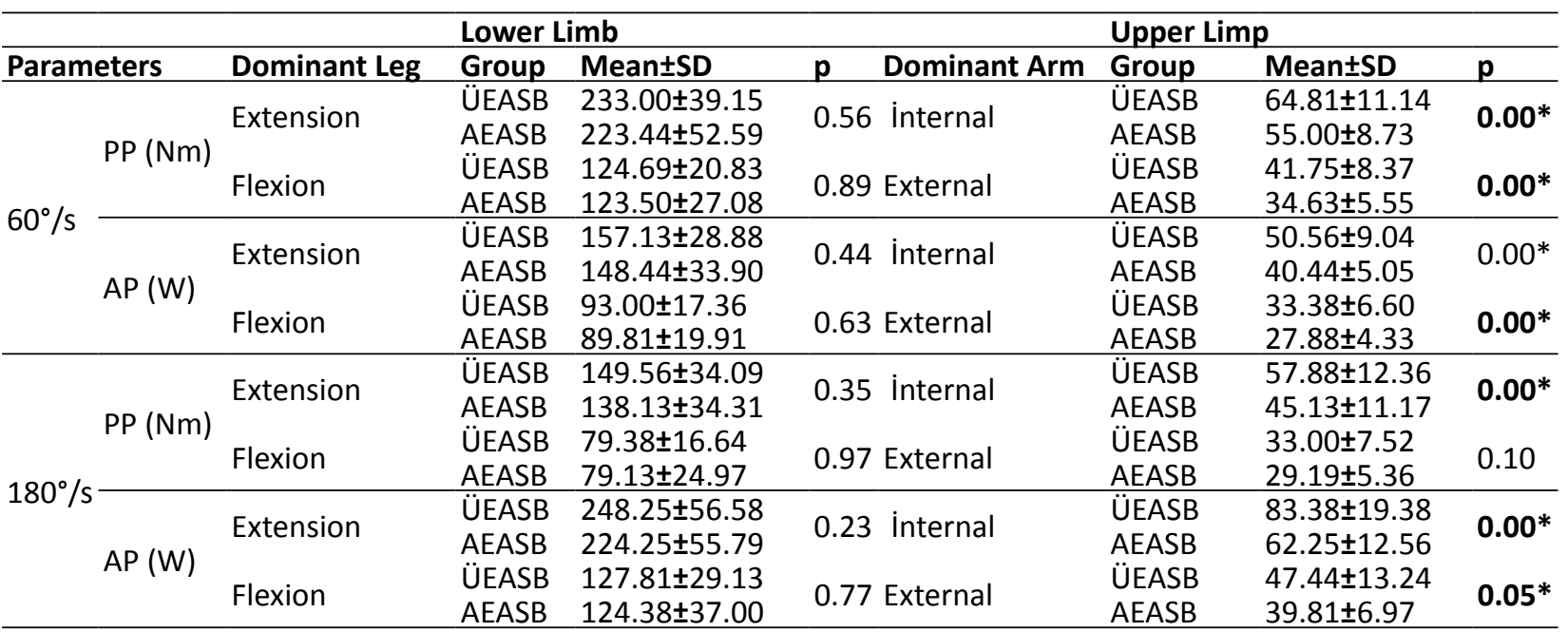

Note. ${ }^{*} p<0.05$. PP - Peak Power. AP - Avarage Power.

Table 7. Correlation analysis between the wingate data of the participants and their dominant leg and arm isokinetic force data at $60 \%$ s and $180 \% \mathrm{~s}$ rotation in terms of extremity dominancy.

\begin{tabular}{|c|c|c|c|c|c|c|c|c|}
\hline \multirow{2}{*}{\multicolumn{2}{|c|}{ Parameters }} & \multirow[t]{2}{*}{ Group } & \multicolumn{2}{|c|}{$\begin{array}{l}\text { Wingate Lower Limb AP } \\
\text { (W) }\end{array}$} & \multirow[t]{2}{*}{ Parameters } & \multirow[t]{2}{*}{ Group } & \multicolumn{2}{|c|}{$\begin{array}{l}\text { Wingate Upper Limp AP } \\
\text { (W) }\end{array}$} \\
\hline & & & & $p$ & & & & $p$ \\
\hline \multirow{8}{*}{$A P(W)$} & Extension $60^{\circ}$ & ÜEASB & $0.74^{* *}$ & 0.00 & \multirow{2}{*}{ İnternal $60^{\circ} / \mathrm{s}$} & ÜEASB & 0.49 & 0.05 \\
\hline & \multirow{3}{*}{ Flexion $60^{\circ} / \mathrm{s}$} & AEASB & $0.55^{*}$ & 0.02 & & AEASB & 0.35 & 0.19 \\
\hline & & ÜEASB & $0.56^{*}$ & 0.02 & \multirow{2}{*}{ External $60^{\circ} / \mathrm{s}$} & ÜEASB & $0.58^{*}$ & 0.01 \\
\hline & & AEASB & 0.42 & 0.10 & & AEASB & 0.17 & 0.52 \\
\hline & Extension & ÜEASB & $0.79^{* *}$ & 0.00 & \multirow[b]{2}{*}{ İnternal $180^{\circ} / \mathrm{s}$} & ÜEASB & 0.45 & 0.08 \\
\hline & $180^{\circ} / \mathrm{s}$ & AEASB & $0.74^{* *}$ & 0.00 & & AEASB & 0.46 & 0.07 \\
\hline & Flexion $180^{\circ} / \mathrm{s}$ & ÜEASB & $0.58^{*}$ & 0.01 & \multirow{2}{*}{ External $180^{\circ} / \mathrm{s}$} & ÜEASB & $0.57^{*}$ & 0.02 \\
\hline & & AEASB & 0.43 & 0.09 & & AEASB & $0.52^{*}$ & 0.03 \\
\hline
\end{tabular}

Note. AP - Avarage Power; **Correlation is significant at 0.01 level. *Correlation is significant at 0.05 level.

\section{Discussion}

There were not any significant differences between the 4 groups' average ages and average heights. The HG's average body weight was significantly higher than the other three groups but there was not any significant body weight difference between the BG, TG and FG.

When the lower extremity wingate results were analysed, it was seen that the PP level of the GH was significantly higher than the BG and $\mathrm{TG}(\mathrm{p}<0.05)$, but the other three groups were similar to each other. The AP parameter was significantly higher in the HG than the BG and TG $(p<0.05)$ but again there was not any significant difference between the other three groups about the AP parameter (Table 2).

Bilge and Tuncel have informed that the RPP group average of elite handball athletes was $8.77 \pm 1.15 \mathrm{~W} / \mathrm{kg}$ [8]. Üstündağ et al. have informed that the elite boxers average RPP was $8.32 \pm 1.21$ and the elite taekwondo athletes' value was $8.53 \pm 0.7$, [9]. Finally, Arslan stated that the elite football athletes' average RPP level was 11,20 W/ 
$\mathrm{kg}$. Hereby with this study the RPP levels were found as $10.5 \pm 1.27$ for the BG, $9.14 \pm 3.89$ for the $\mathrm{HG}, 11.75 \pm 1.98$ for the FG and $9.34 \pm 1.36$ for the TG, so these results are similar to the statements above [10]. Micklewright et al. presented the maximum power level of the regularly exercising 15 healthy males whose average age is 24 and average body weight is $75.4 \mathrm{~kg}$ as $633 \mathrm{~W}$ after doing the leg wingate test in a study conducted to put the difference between athletes and non-athletes [11].

When the upper extremity wingate anaerobic power was examined intergroups, the BG and HG's PP levels were found significantly higher than the TG $(p<0.05)$, and the other averages were similar among the groups. The BG's RPP level was significantly higher than FG and TG, the average values of other groups were significantly similar to each other. The BG and HG were significantly higher than TG in the AP parameter $(\mathrm{p}<0.05)$ and the other AP parameters were similar to each other. For the RAP, the BG's value was significantly higher than the $\mathrm{HG}, \mathrm{FG}$ and TG's ( $\mathrm{p}<0.05$, Table 2).

The literature has valuable researches done for the average RPP values of some athletes [12], Kounalakis et al. has found the elite handball athletes' average RPP as $7.58 \mathrm{~W} / \mathrm{kg}$ [13], Ozan has found the football athletes' value as $6.30 \pm 3.93 \mathrm{~W} / \mathrm{kg}$ and the taekwondo athletes' RPP level as $7.32 \pm 1.19 \mathrm{~W} / \mathrm{kg}$. The results came from these various studies differ from the findings of the study hereby. These differences can be explained by the different performance levels of the groups and by some individual differences such as the body weights of participants [14].

Determining the optimal load is very critical for the aforementioned-type studies and this value is one of the essential sources of differences. Thereby the differences between the power outcomes are related to the ages, body weights and lean body weights. On the other hand, the determination of the optimal load for the wingate anaerobic power test has not reached a final and certain solution yet [6].

In terms of the groups' dominant leg extension and flexion isokinetic outputs at $60 \%$ and $180 \%$ s rotation, the $\mathrm{HG}$ and FG's values were significantly higher than TG at $60 \%$ sP extension, the BG and TG's values were significantly higher at $60 \% \mathrm{~s}$ PP flexion but the $\mathrm{HG}$ and FG were similar to each other at $60 \%$ sP flexion $(p<0.05)$, (Table 3).

The HG's $180^{\circ}$ /s extension PP level were significantly higher than the BG and TG's values and similar to FG's; the FG's value was significantly higher than the TG's. There was no significant difference between the $180 \%$ s flexion PP levels of the groups (Table 3).

In a similar study Hammami et al. has found the dominant leg extension level at $60 \%$ s rotation for the elite taekwondo athletes as $231.26 \pm 16.54$, the flexion value at $60 \%$ s rotation as $129.83 \pm 25.54$, the dominant le extension at $180^{\circ} / \mathrm{s}$ as $132.37 \pm 18.23$, the flexion value as $95.77 \pm 17.65$ [15]. Kocahan et al. has stated the dominant leg extension PP level of elite boxers at $60 \%$ s rotation is $212 \mathrm{~N} / \mathrm{m}$, and the flexion PP level at $240 \%$ s rotation is $85 \mathrm{~N} / \mathrm{m}$ and the extension value is $123 \mathrm{~N} / \mathrm{m}$ [16]. Kafkas and Çoksevim has stated the dominant leg extension level at $60 \%$ rotation of handball athletes actively playing as $149.02 \pm 9.1$, the $60 \%$ s flexion as $93.14 \pm 22.03,90 \% \mathrm{~s}$ extension as $214.86 \pm 31.0090^{\circ}$ s flexion as $110.10 \pm 28.0$ [17]. Özkan has found the dominant leg extension level of elite football athletes at $60^{\circ} / \mathrm{s}$ rotation as $133.1 \pm 17.3$, the flexion level at $60^{\circ} / \mathrm{s}$ rotation as $92.6 \pm 60.3$ [18].

There are different results in the studies present in the literature. The reasons for the higher dominant leg isokinetic values at $60 \% \mathrm{~s}$ and $180 \%$ s obtained in our study and the absence of similarity between the other existing studies are thought to source from the differences between the study groups' level of leagues and their performances.

When the internal and external isokinetic outputs of the dominant arms at $60 \% \mathrm{~s}$ and $180 \%$ s rotation are analysed in detail, it can be seen that there is not any significant difference between the groups' $60 \%$ s internal and external PP levels. However, if the $60 \%$ internal and external averages are taken into consideration, it is obvious that the average values of $\mathrm{BG}$ and $\mathrm{HG}$ in which the upper extremities are used more intensively are higher than the FG and TG's. As in $60 \%$ s PP, the average $180 \%$ s internal and external PP levels are higher in the $\mathrm{BG}$ and $\mathrm{HG}$ in which the upper extremities are used predominantly than the FG and TG. Having said that, the average internal $180 \%$ s levels of the BG, HG and FG were found significantly higher than the TG's $(p<0.05)$. Although there was no significant difference between the external $180^{\circ} / \mathrm{s}$ PP levels of the groups, again the group averages of the $\mathrm{BG}$ and $\mathrm{HG}$ in which the upper extremities are used more intensively were higher than the FG and TG's. These results make us think that the arm force of the athletes who participate in upper-extremity dominant sport branches is higher than the other branches (Table 3).

The outputs of the literature survey indicate some similarities to our study. Kocahan et al. stated the $60 \% \mathrm{~s}$ internal rotation PP level of elite boxers as $67 \mathrm{~N} / \mathrm{M}$, the eternal value as $33 \mathrm{~N} / \mathrm{m}$, the $240 \%$ internal $P P$ as $65 \mathrm{~N} / \mathrm{m}$ and the external value as $27 \mathrm{~N} / \mathrm{m}$ [16]. Franceshini et al. stated the $60 \%$ internal PP level as $57.05 \pm 17.73$, the external value as $35.48 \pm 9.63$ and $180 \%$ internal rotation PP level as $51.45 \pm 10.09$, the external level as $36.17 \pm 9.44$ among the male volleyball athletes who were below the age of 17 [19]. The study's slightly lower average values than our data draw the attention. This difference is thought to be originated from especially the age average. Similarly, Aguada-Hanche et al. has found the $60 \%$ internal rotation AP level as $20.28 \pm 4.02$, the external $60 \%$ s as $14.57 \pm 3.27$, the $180 \%$ s internal as $19.96 \pm 4.08$ and the external level as $15.38 \pm 2.96$ among the elite swimmers whose average age was $13.2 \pm 1.1$ years [20]. Not only the PP values but also AP values were also different in this case due to the lower age average. Indeed, as also evidenced within the study hereby, the important effect of the age on the force is expressed in the literature.

When the relationship between the wingate results and isokinetic forces of the groups are looked at, it can be seen that all groups' $60 \%$ s extension and flexion, $180 \% \mathrm{~s}$ extension and flexion values are positively correlated with 
the lower extremity wingate results. This correlation is at the significant level among the HG's $60 \%$ s extension, $180^{\circ}$ s extension and $180 \%$ s flexion values (Table 4 ).

A positive correlation was confirmed between all groups' upper extremity wingate results and their isokinetic forces. This positive correlation was at a statistically significant level for the BG's internal $60 \%$ s- $180 \%$ s AP levels and wingate AP level, so a strong relationship was determined according to the correlation level. Similarly, there were a significantly strong correlation between the HG's external $180^{\circ}$ /s value and the wingate upper extremity level. Hence, a general positive correlation between the isokinetic and wingate upper and lower extremity values was established in this study. This correlation was found stronger for the specific groups (Table 4). Similarly, Başpınar [21] has determined an important correlation between the lower extremity isokinetic force and 30 and $10 \mathrm{~m}$ speed $60 \%$ s flexion in a study in which the relationship between isokinetic muscle force and anaerobic force of the young football athletes aged 5-16 was examined. However, no difference was stated between the 30 and $10 \mathrm{~m} 60^{\circ} / \mathrm{s}$ extension and 180 $\%$ s extension and flexion in the same study [21].

Bozoğlu informed that the upper extremity isokinetic and wingate levels were positively correlated and this correlation was significant for the $60 \%$ s and $180 \% \mathrm{~s}$ external rotation and arm wingate values in a study conducted with 17 tennis athletes whose average age was $24.15 \pm 2.7$ years [22].

When the groups' lower extremity power wingate power averages are examined according to the extremity dominancy, the results showed that there was no significant difference between UEASB ( $\mathrm{HG}$ and $\mathrm{BG}$ ) and AEASB (TG and FG) in terms of the PP, RPP, AP and RAP levels. However, the expectation was that the values of the branches in which the lower extremities are dominantly used (AEASB) would be higher. The similarity can be explained by the performance of the groups (Table 5). Similarly, Ozan et al. have found that there was not any significant difference between the boxing, football, taekwondo and bicycling groups' lower extremity PP, RPP and AP wingate averages whose age average was 21-22 years [23]. The conjunct evaluation of the data resulted from the study hereby with the Ozan's study in which some similar parameters such as $75 \mathrm{gr} / \mathrm{kg}$ load and similar age and body weight averages shows that the lower extremity anaerobic power parameters do not differ significantly within the branch.

When the groups' upper extremity wingate power averages are examined according to the extremity dominancy, the results showed that the UEASB groups' PP, RP, AP and RAP levels were significantly higher than the AEASB groups' $(p<0.05)$, (Table 5). Similarly again, Ozan et al. have found that the lower extremity PP and RPP averages of the boxers and Greco-roman wrestlers who use their upper extremities dominantly are significantly similar to the bicycling and football groups', but the arm wingate PP and RPP levels of the boxers and Greco-roman wrestlers were significantly higher than the taekwondo and football athletes $(\mathrm{p}<0.05)$ [23]. The difference confirmed on the upper extremities is not detected, at least in a statistical manner, on the lower extremities between the UEASB and AEASB groups. This situation can be originated not only from many individual specialties but also from the performance levels and conditions at the time of measurement. On the other hand, the evaluations of some other studies like Ozan et al. strengthen the conclusions. Indeed, the lower extremities take an important role in the branches that use upper extremities dominantly. On the contrary, the activeness level of the upper extremities in the lower extremity dominant branches reviewed in this study (football, taekwondo) may not be in the foreground as much as the lower extremities' in the upper extremity dominant branches [23]. Both the results we get and the similar research support our standpoint.

When the groups' dominant leg isokinetic force results at $60 \%$ s and $180 \%$ s rotation in terms of the extremity dominancy, the results showed that there was no significant difference between the UEASB and AEASB groups in both the $60 \%$ s extension and flexion PP and AP averages and the $180 \%$ s extension and flexion PP and AP averages (Table 6). Similarly Teixeira et al. stated that the dominant leg extension and flexion PP averages at $60 \% \mathrm{~s}$ and $180 \%$ s rotation were significantly similar between the elite football players whose age averages were 23,29 $\pm 2,55$ years and 23,32 $\pm 2,12$ years [24]. Bamaç et al. (2008) stated that the dominant leg power PP levels of the 20 volleyball athletes whose age average was $19,55 \pm 5$ years and the 20 elite basketball athletes whose age average was $23,06 \pm 7$ at $60 \%$ s and $180 \%$ s extension and flexion were similar in a study which included a control group, but the values were significantly higher $(p<0,05)$ than the control group for both of the athlete groups [25]. No significant difference was detected between the branches in which a dominant extremity is used in terms of dominant leg isokinetic levels in the study. The similar results were supported by the studies states above. The parallelism between the results and lower extremity wingate outputs draws attention

When the groups' dominant arm isokinetic force results at $60 \%$ and $180 \%$ s rotation in terms of the extremity dominancy, the results showed that the internal and external PP levels at $60 \% \mathrm{~s}$ rotation, the internal and external AP levels at $60 \% \mathrm{~s}$, the internal and external AP levels at $180^{\circ} / \mathrm{s}$, and the internal PP level at $180^{\circ} / \mathrm{s}$ rotation of the UEASB groups were significantly higher $(p<0,05)$, but the external PP level at $180^{\circ} / \mathrm{s}$ rotation was statistically similar. The dominant arm parameters of the UEASB group were significantly higher $(p<0,05)$ in general. Thus, the results gained from the upper extremity dominant branches (the $\mathrm{HG}$ and $\mathrm{BG}$ ) supported the deduction (Table 6).

Similarly, Boyios et al. stated that the $60 \% \mathrm{~s}$ internal level of 15 handball athletes who are at 1 . league and whose age average is $24.9 \pm 2.09$ is $60.78 \pm 10.79$, their $60 \%$ s external level is $36.44 \pm 7.23,180 \%$ s internal level is $52.56 \pm 9.23,180^{\circ} / \mathrm{s}$ external level is $28.57 \pm 5.19$ [26]. 
Tasiopoulos et al. (2018) have found the $60 \%$ s internal rotation concentric PP level of 22 elite level boxers whose age average is $25.7 \pm 2,9$ as $56.7 \pm 4.8$, the eccentric power level as 62.6 , the $60 \%$ s external rotation concentric PP level as $32.1 \pm 2.9$, the eccentric as $42.0 \pm 4.2$, and the average $60 \%$ s external power level as 37.05. Again thanks to this study they stated the boxers' $180^{\circ} / \mathrm{s}$ internal rotation concentric PP level was $46.6 \pm 5.0$, the eccentric power level was $62.0 \pm 5.0$, the $180 \%$ s internal PP level was 54.3 , the eccentric PP level at $180^{\circ}$ /s external rotation was $28.2 \pm 2.8$, the eccentric level was $39.5 \pm 2.8$ and the average $180^{\circ}$ s external PP level was 33.85 . Both of the studies aforementioned are highly similar to the study in terms of the isokinetic PP levels of both elite handball athletes and elite boxers [27]. However, the literature research don does not give a sufficient number of comparative researches for the lower and upper extremities dominancy. The related studies generally concentrated on the comparison of some certain branches and groups. So, it is expected that this study can be a norm for the potential research of the literature.

Positive correlations were found between the UEASB and AEASB in the lower extremity dominancy at $60 \% \mathrm{~s}$ and $180 \%$ s rotation and the lower extremity wingate AP levels. This correlation was strong for the UEASB at $60 \%$ and $180 \%$ s extension and was at a moderate level at $60 \%$ and $180 \%$ s flexion for the same group. The correlation was at a moderate level for the AEASB group at $60 \% \mathrm{~s}$ extension, was weak at $60 \%$ s flexion, was strong at $180 \% \mathrm{~s}$ extension and finally was weak at $180^{\circ}$ /s flexion. When the relationship between the upper extremity dominancy at $60 \% \mathrm{~s}$ ve $180 \% \mathrm{~s}$ rotation of the UEASD and AEASB groups and their wingate upper extremity AP levels, positive correlations were detected in general. However, this correlation was weak or at a moderate level according to the outputs of the correlation matrixes (Table 7).

In a study conducted for evaluating the correlation between the speed and force levels of young football athletes, Peñailillo et al. stated a negative correlation at $5 \mathrm{~m}$ speed $(\mathrm{r}=-0.40)$, a strong negative correlation in 15 $\mathrm{m}$ speed $(\mathrm{r}=-0.72)$, a moderate level negative correlation in $20 \mathrm{~m}(\mathrm{r}=0.067)$ [28]. Bozoğlu stated a moderate level correlation between the upper extremity and leg wingate power levels in the $60 \% \mathrm{~s}$ internal PP levels and a weak correlation in the AP levels in a study conducted with 17 tennis athletes whose age average was $24.15 \pm 2.7$ [22].

As a result, it was found that there is a correlation between the isokinetic force parameters and wingate levels and this correlation is stronger in lower extremities when compared to upper extremities. Not only the isokinetic arm force bot also the arm wingate levels were found significantly higher in the branches in which the upper extremities are used dominantly than the branches in which the lower extremities are used dominantly $(p<0.05)$. However, this difference found in upper extremities was not detected in the lower extremities. Apparently, this situation arises from the fact that the existence of high level physical dynamism of the lower extremity in the branches in which the upper extremities are used dominantly (the BG and $\mathrm{HG}$ ) is not valid for the upper extremities in the branches in which the lower extremities are used dominantly (the FG and TG).

\section{Acknowledgments}

We thank to the participant athletes for their precious time and patience.

\section{Conflict of interests}

The authors have no conflict of interests to declare.

\section{References}

1. Baser E. Applied sports psychology. BSY Publications; 1985. (In Turkish).

2. Zorba E, Ziyagil M, Erdemli İ: Comparison of Some Physiological Capacity and Anthropometric Structures of Turkish and Russian Boxing National Teams. Gazi University Journal of Physical Education and Sport Sciences, 1999;1:17-28. (In Turkish).

3. Prentice WE, Voight ML. Techniques in musculoskeletal rehabilitation. McGraw Hill Professional; 2001.

4. Bencke J, Damsgaard R, Sækmose A, Jørgensen $\mathrm{P}$, Jørgensen $\mathrm{K}$, Klausen $\mathrm{K}$ : Anaerobic power and muscle strength characteristics of 11 years old elite and non-elite boys and girls from gymnastics, team handball, tennis and swimming. Scandinavian Journal of Medicine \& Science in Sports, 2002, 12:171-178. https://doi.org/10.1034/j.1600-0838.2002.01128.x

5. McArdle WD, Katch FI, Katch VL. Exercise physiology: nutrition, energy, and human performance. Lippincott Williams \& Wilkins; 2010.

6. Özkan A, Köklü Y, Ersöz G. Anaerobic performance and measurement methods. Ankara Offset Printing; 2010. (In Turkish).

7. Mendonça LDM, Bittencourt NFN, Anjos MTSd, Silva
AAd, Fonseca ST. Isokinetic muscular assessment of the shoulder joint in athletes from the male under-19 and under-21 Brazilian volleyball teams. Revista Brasileira de Medicina do Esporte, 2010;16:107-111. https://doi.org/10.1590/S1517-86922010000200006

8. Billge M, Tuncel F. Investigation of the Relationship between Anaerobic Power and Capacity and Body Composition in Handball Players. Gazi Journal of Physical Education and Sport Sciences, 2003;8:67-76. (In Turkish).

9. Ustundăg B, Kocahan T, Tortu E, Karaman G, Delİceoğlu G. Investigation of Anaerobic Power and Capacity of Male National Team Athletes in Different Branches. Gaziantep University, Journal of Sport Sciences, 2017; 2:57-65. (In Turkish).

10.Arslan O. Evaluating the anaerobic power values and sprint performances of amateur football players playing in different positions. Ondokuz May1s University, Department of Physical Education and Sports; 2010. (In Turkish).

11. Micklewright D, Alkhatib A, Beneke R. Mechanically versus electro-magnetically braked cycle ergometer: performance and energy cost of the Wingate Anaerobic Test. European Journal of Applied Physiology, 2006; 96:748-751. https://doi.org/10.1007/s00421-006-0145-5

12.Kounalakis SN, Bayios IA, Koskolou MD, Geladas 
ND. Anaerobic capacity of the upper arms in toplevel team handball players. International Journal of Sports Physiology and Performance, 2008;3:251-261. https://doi.org/10.1123/ijspp.3.3.251

13.Hübner-Wozniak E, Kosmol A, Glaz A, Kusior A. The evaluation of upper limb muscles anaerobic performance of elite wrestlers and boxers. J Sci Med Sports, 2006;7:472-480.

14.Ozan M. Evaluation of anaerobic power with arm and leg wingate tests in athletes. Selcuk University, Institute of Health Sciences, 2013. (In Turkish).

15.Hammami N, Zinoubi B, Hamdi F, Nouri A, Zouita A, Dziri C. Profil isocinétique des muscles du genou chez des taekwondoïstes élites olympiques. Science \& Sports, 2013;28:188-195. https://doi.org/10.1016/j.scispo.2013.01.003

16.Kocahan T, Akinoğlu B, Yildirim NÜ. Shoulder and knee joints of Turkey's National Men's Boxing Team Athlete Profile Determination of isokinetic muscle strength. Journal of Physiotherapy Rehabilitation, 2018; 29:37-43. (In Turkish).

17.Kafkas A, Çoksevİm B. The Effect of Isokinetic Exercise Programs on Athletes' Upper and Lower Extremity Muscle Groups. İnönü University. Journal of Physical Education and Sport Sciences, 2014;1:10-21. (In Turkish).

18.Özkan A, Mitat K, Ersöz G. Determining the optimal load Wingate anaerobic power test. (Spormetre) Physical Education and Sport Sciences Journal, 2011;9:1-5. (In Turkish).

19.Franceschini K, Nissola N, Zardo B, Tadielo G, Bonetti L. Isokinetic performance of shoulder external and internal rotators in adolescent male volleyball athletes. International Archives of Medicine, 2016: 9. https://doi.org/10.3823/2011

20.Aguado-Henche S, de Arce AS, Carrascosa-Sánchez J, Bosch-Martín A, Cristóbal-Aguado S. Isokinetic assessment of shoulder complex strength in adolescent elite synchronized swimmers. Journal of Bodywork and Movement Therapies, 2018;22:968-971. https://doi.org/10.1016/j.jbmt.2018.01.018

21.Başpınar Ö. The effect of isokinetic muscle strength on anaerobic power in soccer players. Pamukkale University, Institute of Health Sciences; 2009. (In Turkish).

22.Bozoğlu MS. Relationship between shoulder functional ratio and anaerobic power. Selcuk University, Institute of Health Sciences; 2014. (In Turkish).

23.Ozan M,Kiliç M, ÇakmakçıO.AssessmentofAnaerobic Power With Arm and Leg Wingate Tests InAthletes. European Journal of Physical Education and Sport Science.2018;4(3):49-60. https://doi.org/10.5281/zenodo.1203780

24.Teixeira J, Carvalho P, Moreira C, Carneiro A, Santos R. Muscle strength assessment of knee flexors and extensors. comparative study between basketball, football, handball and volleyball athletes. Int J Sports Sc, 2015;5:192-192.

25.Bamaç B, Çolak T, Özbek A, Çolak S, Cinel Y, Yenigün Ö. Isokinetic performance in elite volleyball and basketball players. Kinesiology: International Journal of Fundamental and Applied Kinesiology, 2008;40:183-189.

26.Bayios IA, Anastasopoulou E, Sioudris D, Boudolos KD. Relationship between isokinetic strength of the internal and external shoulder rotators and ball velocity in team handball. Journal of Sports Medicine and Physical Fitness, 2001;41:229-235.

27.Tasiopoulos I, Nikolaidis PT, Tripolitsioti A, Stergioulas A, Rosemann T, Knechtle B. Isokinetic characteristics of amateur boxer athletes. Frontiers in Physiology, 2018; 9. https://doi.org/10.3389/fphys.2018.01597

28.Peñailillo L, Espíldora F, Jannas-Vela S, Mujika I, ZbindenFoncea H. Muscle strength and speed performance in youth soccer players. Journal of Human Kinetics, 2016;50:203-210. https://doi.org/10.1515/hukin-2015-0157

\section{Information about the authors:}

Samet Aktaş; (Corresponding Author); https://orcid.org/0000-0001-6857-2599; sametaktas85@hotmail.com; School of Physical Education and Sport, University of Batman; Batman, Turkey.

Oktay Çakmakçı; https://orcid.org/0000-0002-8612-1334; ocakmakci@gmail.com; Faculty of Sport Sciences, University of Selcuk; Konya, Turkey.

Cite this article as:

Aktaş S, Çakmakçı O. Examination of lower-upper limb of power and force parameters of elite athletes. Physical Education of Students, 2020;24(6):340-347.

https://doi.org/10.15561/20755279.2020.0606

This is an Open Access article distributed under the terms of the Creative Commons Attribution License, which permits unrestricted use, distribution, and reproduction in any medium, provided the original work is properly cited http://creativecommons.org/licenses/by/4.0/deed.en

Received: 09.10.2020

Accepted: 03.12.2020; Published: 30.12.2020 